ORIGINAL ARTICLE

\section{Effect of Valsartan on the Incidence of Diabetes and Cardiovascular Events}

\author{
The NAVIGATOR Study Group*
}

\section{BACKGROUND}

It is not known whether drugs that block the renin-angiotensin system reduce the risk of diabetes and cardiovascular events in patients with impaired glucose tolerance.

\section{METHODS}

In this double-blind, randomized clinical trial with a 2-by-2 factorial design, we assigned 9306 patients with impaired glucose tolerance and established cardiovascular disease or cardiovascular risk factors to receive valsartan (up to $160 \mathrm{mg}$ daily) or placebo (and nateglinide or placebo) in addition to lifestyle modification. We then followed the patients for a median of 5.0 years for the development of diabetes (6.5 years for vital status). We studied the effects of valsartan on the occurrence of three coprimary outcomes: the development of diabetes; an extended composite outcome of death from cardiovascular causes, nonfatal myocardial infarction, nonfatal stroke, hospitalization for heart failure, arterial revascularization, or hospitalization for unstable angina; and a core composite outcome that excluded unstable angina and revascularization.

\section{RESULTS}

The cumulative incidence of diabetes was $33.1 \%$ in the valsartan group, as compared with $36.8 \%$ in the placebo group (hazard ratio in the valsartan group, 0.86 ; $95 \%$ confidence interval [CI], 0.80 to $0.92 ; \mathrm{P}<0.001$ ). Valsartan, as compared with placebo, did not significantly reduce the incidence of either the extended cardiovascular outcome ( $14.5 \%$ vs. $14.8 \%$; hazard ratio, 0.96 ; $95 \% \mathrm{CI}, 0.86$ to $1.07 ; \mathrm{P}=0.43$ ) or the core cardiovascular outcome $(8.1 \%$ vs. $8.1 \%$; hazard ratio, $0.99 ; 95 \% \mathrm{CI}, 0.86$ to $1.14 ; \mathrm{P}=0.85$ ).

\section{CONCLUSIONS}

Among patients with impaired glucose tolerance and cardiovascular disease or risk factors, the use of valsartan for 5 years, along with lifestyle modification, led to a relative reduction of $14 \%$ in the incidence of diabetes but did not reduce the rate of cardiovascular events. (ClinicalTrials.gov number, NCT00097786.)
The authors are listed in the Appendix. Address reprint requests to Dr. Robert M. Califf at the Duke Translational Medicine Institute, P.O. Box 17969, Durham, NC27715, or at calif001@mc.duke.edu.

*The names of the investigators and members of the committees in the $\mathrm{Na}$ teglinide and Valsartan in Impaired Glucose Tolerance Outcomes Research (NAVIGATOR) Study Group are listed in Supplementary Appendix 1, available with the full text of this article at NEJM.org.

This article (10.1056/NEJMoa1001121) was published on March 14, 2010, and was last updated on March 29, 2010, at NEJM.org.

N EngIJ Med 2010;362:1477-90.

Copyright (c) 2010 Massachusetts Medical Society. 
P ATIENTS WITH IMPAIRED GLUCOSE TOLerance have an increased risk of type 2 diabetes mellitus and cardiovascular disease. ${ }^{1-3}$ Interventions that might reduce the incidence of diabetes and associated rates of death and complications from cardiovascular causes in such patients are therefore of importance. ${ }^{3}$ Several trials have shown that lifestyle modification, including increased physical activity and weight loss, reduces the risk of diabetes, although these trials did not evaluate cardiovascular outcomes. ${ }^{3-8}$ Certain drugs, including metformin, acarbose, and rosiglitazone, also reduce the incidence of diabetes, although their effect on cardiovascular events is uncertain. ${ }^{6,9,10}$

Another pharmacologic approach to reducing the risk of diabetes and cardiovascular disease is inhibition of the renin-angiotensin system. Some studies have shown that angiotensin-convertingenzyme (ACE) inhibitors and angiotensin-receptor blockers (ARBs) may reduce the incidence of diabetes and the risk of cardiovascular events among patients with hypertension and other cardiovascular diseases. ${ }^{11-14}$ In most of these studies, however, the incidence of diabetes was not the primary outcome of the trial, nor was it confirmed by systematic glucose measurement. ${ }^{15}$

A single trial, the Diabetes Reduction Assessment with Ramipril and Rosiglitazone Medication (DREAM) study (ClinicalTrials.gov number, NCT00095654), attempted to prospectively and robustly ascertain the effect of an ACE inhibitor in a population at high risk for diabetes, although the study did not test this treatment in addition to lifestyle modification and was not powered to evaluate cardiovascular outcomes. ${ }^{16}$ Ramipril did not reduce the incidence of diabetes, although plasma glucose levels measured 2 hours after an oral glucose load were significantly lower in the ramipril group. ${ }^{16}$

We conducted a large, prospective trial, called Nateglinide and Valsartan in Impaired Glucose Tolerance Outcomes Research (NAVIGATOR), to evaluate whether nateglinide, a blood glucoselowering drug in the meglitinide class, or valsartan, an ARB, would reduce the risk of diabetes and cardiovascular events among patients with impaired glucose tolerance and established cardiovascular disease or cardiovascular risk factors. This treatment was tested in addition to lifestyle modification. ${ }^{17}$ Here we report the results of the valsartan portion of the study; the results of the nateglinide portion are discussed elsewhere in this issue of the Journal. ${ }^{18}$

METHODS

\section{STUDY PATIENTS}

From January 2002 through January 2004, we recruited patients at 806 centers in 40 countries. All eligible patients had impaired glucose tolerance, ${ }^{3}$ a fasting plasma glucose level of at least $95 \mathrm{mg}$ per deciliter (5.3 mmol per liter) but less than $126 \mathrm{mg}$ per deciliter (7.0 mmol per liter), and one or more cardiovascular risk factors (if 55 years of age or older) or known cardiovascular disease (if 50 years of age or older). A screening glucose-tolerance test was performed 2 hours after a 75-g oral glucose load to determine study eligibility. Impaired glucose tolerance was defined as a post-load plasma glucose level of at least $140 \mathrm{mg}$ per deciliter (7.8 mmol per liter) but less than $200 \mathrm{mg}$ per deciliter (11.1 mmol per liter). ${ }^{3}$ (For details, see Section 2 in Supplementary Appendix 1, available with the full text of this article at NEJM.org.)

Exclusion criteria were laboratory abnormalities or conditions that could interfere with assessment of the safety or efficacy of a study drug, the use of an ACE inhibitor or ARB for the treatment of hypertension (although ACE inhibitors were allowed for other indications), and the use of an antidiabetic medication within the previous 5 years. ${ }^{17}$

The trial was approved by each center's ethics committee. All patients provided written informed consent.

\section{STUDY TREATMENT}

We used a computerized, interactive voice-response telephone randomization system involving concealed study-group assignments to randomly assign patients to valsartan or matching placebo (and nateglinide or matching placebo) in a 2-by-2 factorial design. Randomization was stratified according to center, with a block size of eight within each center. Valsartan was started at a dose of $80 \mathrm{mg}$ once daily, with an increase after 2 weeks to $160 \mathrm{mg}$ once daily; dose reduction or interruption because of adverse events or for other clinical reasons was permitted. 


\section{LIFESTYLE MODIFICATION}

All patients were required to participate in a studyspecific lifestyle-intervention program that was designed to reduce the risk of diabetes. The objective of the intervention was to help patients achieve and maintain a 5\% weight loss, reduce intake of saturated and total dietary fat, and increase physical activity to 150 minutes weekly (see Section 3 in Supplementary Appendix 1). Site personnel were trained to administer this program and provided materials designed to facilitate adherence at each clinic visit, with reinforcement and monitoring by telephone between study visits.

\section{STUDY PROCEDURES}

After the dose-adjustment phase, patients were seen every 6 months. Fasting plasma glucose levels were measured every 6 months for the first 3 years and then annually. Oral glucose tolerance tests were performed yearly. The morning dose of a study drug was delayed until after glucose levels had been measured.

\section{STUDY OUTCOMES}

\section{Coprimary Outcomes}

Initially, there were two coprimary outcomes: the incidence of diabetes and an extended cardiovascular outcome, a composite of death from cardiovascular causes, nonfatal myocardial infarction, nonfatal stroke, hospitalization for heart failure, arterial revascularization, or hospitalization for unstable angina. A third coprimary core cardiovascular outcome (a composite of death from cardiovascular causes, nonfatal myocardial infarction, nonfatal stroke, and hospitalization for heart failure), which was initially a secondary composite outcome, was added, as described previously. ${ }^{17,19}$

\section{Incidence of Diabetes}

Diabetes was defined as a fasting plasma glucose level of $126 \mathrm{mg}$ per deciliter (7.0 mmol per liter) or more or a plasma glucose level of $200 \mathrm{mg}$ per deciliter (11.1 mmol per liter) or more as measured 2 hours after an oral glucose load, ${ }^{20,21}$ confirmed within 12 weeks by a glucose tolerance test. The date of onset of diabetes was defined as the date of the first diagnostic glucose value. An independent committee whose members were not aware of study-group assignments adjudicated the small number of cases in which patients received a diagnosis of diabetes or were started on an an- tidiabetic drug without undergoing the studyspecified laboratory investigations.

\section{Death, Hospitalization, and Other Cardiovascular Events}

An independent committee whose members were unaware of study-group assignments adjudicated the occurrence of death, hospitalization, and potential cardiovascular events that occurred in patients who were not hospitalized (for definitions of these events, see Section 4 in Supplementary Appendix 1).

\section{STUDY OVERSIGHT}

The trial was sponsored by Novartis Pharma and was designed in collaboration with an academic executive committee and monitored by an independent safety committee. ${ }^{17}$ Data were collected, managed, and analyzed by the sponsor, with oversight from the executive committee, and the analyses were replicated by an independent academic statistician. The manuscript was prepared by a writing group, whose members had unrestricted access to the data, and was subsequently revised by all the authors. All authors decided to submit the manuscript for publication and assume responsibility for its accuracy and completeness. The trial protocol is available in Supplementary Appendix 2.

\section{STATISTICAL ANALYSIS}

On the assumption that the study would continue until the extended cardiovascular outcome occurred in 1374 patients in the two study groups combined, we anticipated a power of $90 \%$ to detect a $20 \%$ reduction in the hazard rate in the valsartan group, assuming subadditivity of the effects of valsartan and nateglinide and allowing for an annual discontinuation rate of $6.9 \% .{ }^{17}$ These calculations were revised after an updated meta-analysis of trials of renin-angiotensin blockers suggesting that the reduction in the hazard of the extended cardiovascular outcome was more likely to be $12 \%$ (providing a power of $64 \%$ ) and $18 \%$ for the core cardiovascular outcome (providing a power of $74 \%$, assuming the occurrence of 784 core events); the estimated power to show a reduction in at least one of the cardiovascular outcomes was 77\%.17,19

While accumulating 1374 extended cardiovascular events, we anticipated that more than 3000 patients would have progression to diabetes, en- 
suring a power of more than $99 \%$ to detect a hazard reduction of $18 \%$. Because we examined the effects of two drugs (valsartan and nateglinide) on three primary outcomes in a factorial manner, we adjusted for the three tests that were performed for each study drug (but not across drugs). Twosided $\mathrm{P}$ values are given, with protocol-specified one-sided values for the coprimary outcomes and their components. The one-sided familywise type I error rate of $2.5 \%$ for each drug was controlled with the use of a closed-testing procedure, with one fifth of the alpha assigned to diabetes and four fifths to the two cardiovascular outcomes, since more cases of incident diabetes than cardiovascular events were anticipated. This allowed for testing of each primary outcome even if the other two outcomes did not show a significant result. An O'Brien-Fleming-type alpha spending approach accounted for the interim efficacy analysis performed with $30 \%$ of the target number of extended cardiovascular events (a one-sided alpha of 0.00004) in November 2005. ${ }^{22}$ (For details, see Section 5 in Supplementary Appendix 1.)

Log-rank tests that were stratified according to a history of cardiovascular disease and nateglinide treatment were used to compare the valsartan and placebo groups for the time to a first event in the extended or core composite outcome. Given the fixed-time schedule for glucose measurement, a discrete time proportional-odds model was used for the incidence of diabetes. We also conducted predefined analyses of the components of the composite cardiovascular outcomes, time to death from any cause, time to cardiovascularrelated hospitalization, indexes of hyperglycemia, and body weight. The possibility of interaction between valsartan and nateglinide was tested for each outcome reported. The effects of study treatment were evaluated in prespecified subgroups. ${ }^{17}$ We compared baseline characteristics, safety, and other trial assessments using summary statistics.

\section{RESULTS}

\section{STUDY PATIENTS}

Of 43,502 patients who underwent screening, 9518 were randomly assigned to treatment. After randomization, 212 patients were excluded from the analysis, since 10 sites were closed because of deficiencies in meeting Good Clinical Practice guidelines, which left 9306 patients who could be evaluated (Fig. 1).

Among patients who were taking a study drug at 6 months, $91.1 \%$ of those who were assigned to receive valsartan were taking the higher dose (160 mg daily); this proportion was $94.6 \%$ in the placebo group $(\mathrm{P}<0.001)$. At 1 year, $77.6 \%$ of patients in the valsartan group were taking a study drug, as compared with $79.2 \%$ of those in the placebo group $(\mathrm{P}=0.06)$. The corresponding proportions in the valsartan group and the placebo group were 72.3 and $73.3 \%$ at 3 years $(\mathrm{P}=0.29)$ and $66.2 \%$ and $66.7 \%$ at 5 years $(\mathrm{P}=0.59)$.

Baseline characteristics were similar in the valsartan and placebo groups. Of the 9306 patients who were evaluated, 2266 (24.3\%) had known cardiovascular disease, mainly coronary artery disease. Of the remainder who had cardiovascular risk factors only, $79.6 \%$ had a history of hypertension.

Patients with cardiovascular disease were treated more intensively at baseline than were those who had risk factors only: $21.5 \%$ received an ACE inhibitor, as compared with $2.7 \%$ of those with risk factors only; $75.8 \%$ received antiplatelet treatment, as compared with $24.2 \%$ of those with risk factors only; $61.7 \%$ received a beta-blocker, as compared with $32.2 \%$ of those with risk factors only; and $64.1 \%$ received lipid-modifying therapy, as compared with $30.2 \%$ of those with risk factors only.

The use of diuretics and calcium-channel blockers was similar in the two groups. The use of nonstudy cardiovascular treatments increased during follow-up (Table 1). ${ }^{23,24}$ At the last study visit, $20.4 \%$ of patients in the valsartan group and $24.0 \%$ of those in the placebo group were receiving an open-label renin-angiotensin inhibitor $(\mathrm{P}<0.001)$. In the placebo group, as compared with the valsartan group, 5.3\% more patients were taking a diuretic, and 3.1\% more were taking a beta-blocker ( $\mathrm{P}<0.001$ for both comparisons).

Blood-pressure levels decreased more in the valsartan group than in the placebo group, with a mean $( \pm S D)$ overall reduction in systolic pressure of $6.3 \pm 14.2 \mathrm{~mm} \mathrm{Hg}$ in the valsartan group, as compared with a reduction of $3.8 \pm 13.8 \mathrm{~mm} \mathrm{Hg}$ in the placebo group (between-group difference, $2.8 \mathrm{~mm} \mathrm{Hg} ; 95 \%$ confidence interval [CI], 2.4 to 3.2 ; $\mathrm{P}<0.001$ ) with adjustment for region, cardiovascular history, and nateglinide treatment (Fig. $2 \mathrm{~A})$. The mean reduction in diastolic pressure was $4.4 \pm 8.4 \mathrm{~mm} \mathrm{Hg}$ in the valsartan group, as compared with a reduction of $3.0 \pm 8.1 \mathrm{~mm} \mathrm{Hg}$ in the placebo group (difference, $1.4 \mathrm{~mm} \mathrm{Hg;} \mathrm{95 \%} \mathrm{CI,}$ 1.2 to 1.7 ; $\mathrm{P}<0.001$ ) (Fig. 2B). There was a small 


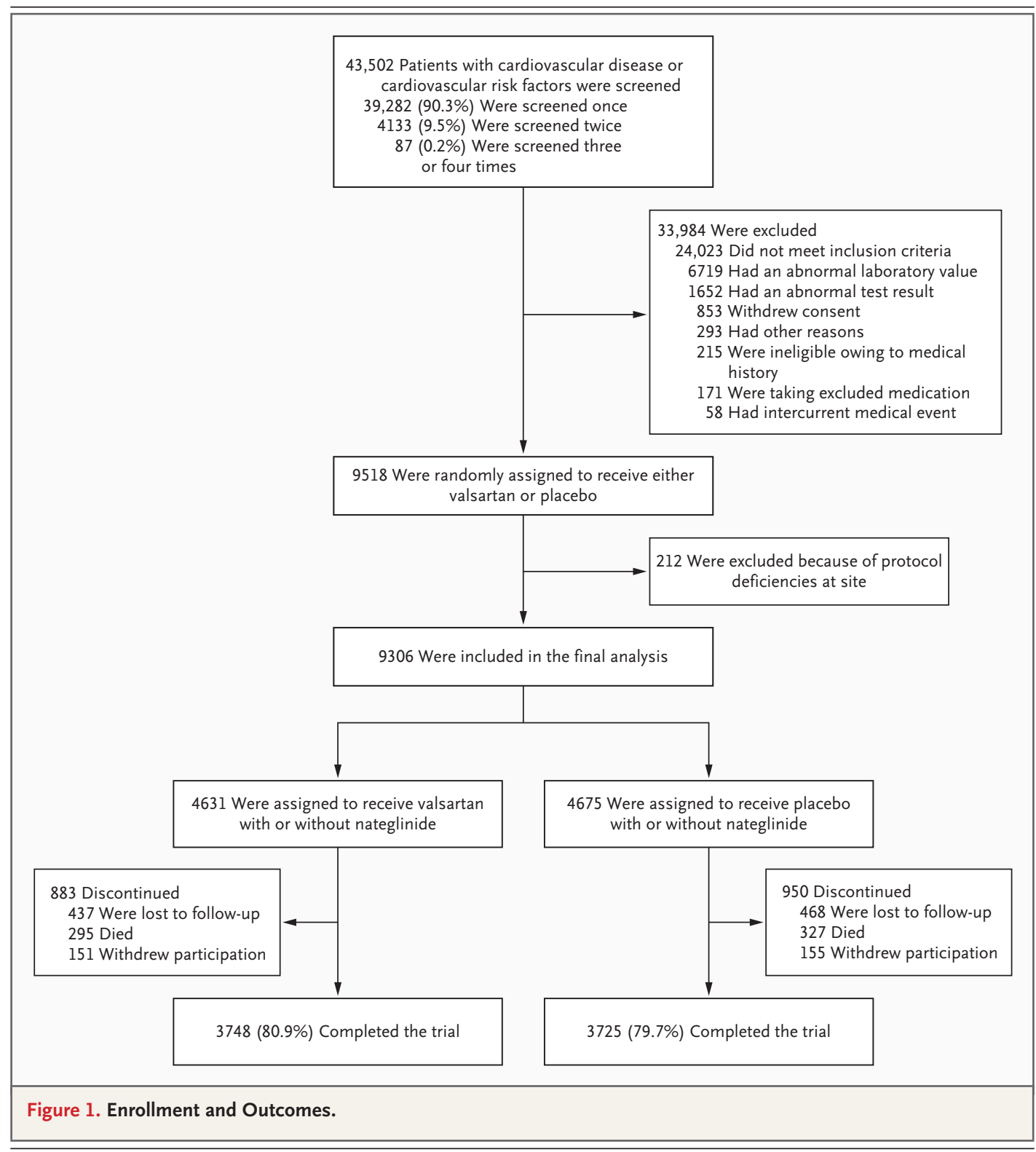

decline in weight during follow-up that was slightly less in the valsartan group $(0.31 \pm 3.9 \mathrm{~kg})$ than in the placebo group $(0.60 \pm 4.0 \mathrm{~kg})$, a difference of $0.28 \mathrm{~kg}$ ( $95 \%$ CI, 0.12 to 0.44 ; P<0.001) (Fig. 2C). There was little change in waist circumference during the study, with an increase of $0.08 \pm 6.5 \mathrm{~cm}$ in the valsartan group, as compared with a decrease of $0.16 \pm 6.5 \mathrm{~cm}$ in the placebo group (difference, $0.20 \mathrm{~cm} ; 95 \% \mathrm{CI},-0.05$ to $0.45 ; \mathrm{P}=0.12$ ) (Fig. 2D).

\section{FOLLOW-UP}

Among surviving patients who had not withdrawn consent and had not received a clinical diagnosis of diabetes, $80 \%$ underwent measurement of fasting plasma glucose or plasma glucose 2 hours after an oral glucose load at the close-out visit or during the final 6 months of the study. The rate of loss to follow-up (including withdrawal of consent) was $12.7 \%$ in the valsartan group (588 patients) and $13.3 \%$ in the placebo group (623 patients). Because many discontinuations occurred late in the study, information on vital status was available for $96 \%$ of possible follow-up time in the two study groups. The median follow-up was 6.5 years for vital status, 6.4 years for the core cardiovascular outcome, 6.3 years for the extended cardiovascular outcome, and 5.0 years for the incidence of diabetes. 


\begin{tabular}{|c|c|c|c|}
\hline Characteristic & $\begin{array}{l}\text { Valsartan } \\
(\mathrm{N}=4631)\end{array}$ & $\begin{array}{l}\text { Placebo } \\
(\mathrm{N}=4675)\end{array}$ & P Value \\
\hline Age $-y r$ & $63.7 \pm 6.8$ & $63.8 \pm 6.8$ & 0.27 \\
\hline Female sex — no. (\%) & $2314(50.0)$ & $2397(51.3)$ & 0.29 \\
\hline \multicolumn{4}{|l|}{ Race - no. $(\%) \dagger$} \\
\hline White & $3849(83.1)$ & $3885(83.1)$ & 0.96 \\
\hline Black & $113(2.4)$ & $123(2.6)$ & \\
\hline Asian & $298(6.4)$ & $315(6.7)$ & \\
\hline Other & $371(8.0)$ & $352(7.5)$ & \\
\hline Weight — kg & $83.5 \pm 17.4$ & $83.8 \pm 17.1$ & 0.38 \\
\hline Body-mass indext & $30.4 \pm 5.5$ & $30.6 \pm 5.3$ & 0.29 \\
\hline \multicolumn{4}{|l|}{ Waist circumference $-\mathrm{cm}$} \\
\hline All patients & $101 \pm 14$ & $101 \pm 14$ & 0.36 \\
\hline Men & $104 \pm 13$ & $104 \pm 12$ & \\
\hline Women & $98 \pm 14$ & $98 \pm 14$ & \\
\hline \multicolumn{4}{|l|}{ Sitting blood pressure $-\mathrm{mm} \mathrm{Hg}$} \\
\hline Systolic & $139.4 \pm 17.8$ & $139.9 \pm 17.1$ & 0.21 \\
\hline Diastolic & $82.5 \pm 10.4$ & $82.6 \pm 10.1$ & 0.93 \\
\hline \multicolumn{4}{|l|}{ Cardiovascular risk factors - no. (\%) } \\
\hline Any & $4565(98.6)$ & $4621(98.8)$ & 0.26 \\
\hline Family history of premature heart disease & $782(16.9)$ & $762(16.3)$ & 0.44 \\
\hline Current smoker & $518(11.2)$ & $507(10.8)$ & 0.59 \\
\hline Hypertension & $3581(77.3)$ & $3635(77.8)$ & 0.62 \\
\hline Left ventricular hypertrophy & $133(2.9)$ & $135(2.9)$ & 0.97 \\
\hline Microalbuminuria & $61(1.3)$ & $53(1.1)$ & 0.42 \\
\hline Reduced HDL cholesterol & $459(9.9)$ & $433(9.3)$ & 0.28 \\
\hline Elevated non-HDL cholesterol & $2066(44.6)$ & $2097(44.9)$ & 0.82 \\
\hline \multicolumn{4}{|l|}{ History of cardiovascular disease — no. (\%) } \\
\hline Any & $1148(24.8)$ & $1118(23.9)$ & 0.30 \\
\hline Myocardial infarction & $552(11.9)$ & $541(11.6)$ & 0.60 \\
\hline Angina or positive stress test & $416(9.0)$ & $400(8.6)$ & 0.47 \\
\hline Percutaneous coronary intervention & $190(4.1)$ & $172(3.7)$ & 0.29 \\
\hline Multivessel coronary-artery bypass grafting & $182(3.9)$ & $198(4.2)$ & 0.46 \\
\hline Intermittent claudication & $42(0.9)$ & $56(1.2)$ & 0.17 \\
\hline Peripheral-artery stenosis & $32(0.7)$ & $22(0.5)$ & 0.16 \\
\hline Lower-limb angioplasty or bypass surgery & $61(1.3)$ & $49(1.0)$ & 0.24 \\
\hline Nontraumatic leg or foot amputation & $5(0.1)$ & $2(<0.1)$ & 0.25 \\
\hline Stroke of atherosclerotic origin & $143(3.1)$ & $132(2.8)$ & 0.44 \\
\hline Family history of diabetes mellitus — no. (\%) & $1737(37.5)$ & $1810(38.7)$ & 0.25 \\
\hline \multicolumn{4}{|l|}{ Glycemic indexes } \\
\hline Fasting plasma glucose $-\mathrm{mmol} / \mathrm{liter}$ & $6.1 \pm 0.45$ & $6.1 \pm 0.45$ & 0.55 \\
\hline Plasma glucose $2 \mathrm{hr}$ after glucose load $-\mathrm{mmol} /$ liter & $9.2 \pm 0.93$ & $9.2 \pm 0.94$ & 0.44 \\
\hline Glycated hemoglobin — \% & $5.79 \pm 0.47$ & $5.82 \pm 0.46$ & 0.08 \\
\hline Metabolic syndrome - no. (\%)』 & $3825(82.6)$ & $3970(85.0)$ & 0.003 \\
\hline
\end{tabular}




\begin{tabular}{|c|c|c|c|}
\hline Characteristic & $\begin{array}{l}\text { Valsartan } \\
(\mathrm{N}=4631)\end{array}$ & $\begin{array}{c}\text { Placebo } \\
(\mathrm{N}=4675)\end{array}$ & P Value \\
\hline \multicolumn{4}{|l|}{ Lipids - mg/dl } \\
\hline Total cholesterol & $210 \pm 42$ & $210 \pm 42$ & 0.78 \\
\hline HDL cholesterol & $50 \pm 13$ & $50 \pm 13$ & 0.67 \\
\hline LDL cholesterol & $126 \pm 37$ & $127 \pm 37$ & 0.99 \\
\hline Triglycerides & $175 \pm 105$ & $173 \pm 103$ & 0.25 \\
\hline Median & 151 & 150 & \\
\hline Interquartile range & 109-209 & $108-209$ & \\
\hline Creatinine $-\mathrm{mg} / \mathrm{dl}$ & $0.9 \pm 0.2$ & $0.9 \pm 0.2$ & 0.29 \\
\hline \multicolumn{4}{|l|}{ Estimated GFR } \\
\hline Mean $-\mathrm{ml} / \mathrm{min} / 1.73 \mathrm{~m}^{2}$ & $80.9 \pm 18.5$ & $80.4 \pm 19.0$ & 0.20 \\
\hline$<60 \mathrm{ml} / \mathrm{min} / 1.73 \mathrm{~m}^{2}-$ no. (\%) & $499(10.8)$ & $521(11.1)$ & 0.53 \\
\hline Ratio of urinary albumin (mg) to creatinine (g) & & & 0.29 \\
\hline Median & 7.1 & 7.1 & \\
\hline Interquartile range & $4.4-14.2$ & $4.5-14.7$ & \\
\hline \multicolumn{4}{|l|}{ Concomitant medication — no. (\%)\| } \\
\hline \multicolumn{4}{|l|}{ ACE inhibitor } \\
\hline Baseline & $351(7.6)$ & $325(7.0)$ & 0.36 \\
\hline Last study visit & $688(14.9)$ & $786(16.8)$ & 0.005 \\
\hline \multicolumn{4}{|l|}{ Angiotensin-receptor blocker } \\
\hline Baseline & $18(0.4)$ & $29(0.6)$ & 0.12 \\
\hline Last study visit & $275(5.9)$ & $353(7.6)$ & 0.002 \\
\hline \multicolumn{4}{|l|}{ Alpha-blocker } \\
\hline Baseline & $289(6.2)$ & $288(6.2)$ & 0.87 \\
\hline Last study visit & $213(4.6)$ & $260(5.6)$ & 0.04 \\
\hline \multicolumn{4}{|l|}{ Beta-blocker } \\
\hline Baseline & $1863(40.2)$ & $1803(38.6)$ & 0.15 \\
\hline Last study visit & $1840(39.7)$ & $2000(42.8)$ & $<0.001$ \\
\hline \multicolumn{4}{|l|}{ Calcium-channel blocker } \\
\hline Baseline & $1483(32.0)$ & $1529(32.7)$ & 0.46 \\
\hline Last study visit & $1537(33.2)$ & $1857(39.7)$ & $<0.001$ \\
\hline \multicolumn{4}{|l|}{ Diuretic } \\
\hline Baseline & $1451(31.3)$ & $1509(32.3)$ & 0.36 \\
\hline Last study visit & $1578(34.1)$ & $1841(39.4)$ & $<0.001$ \\
\hline \multicolumn{4}{|l|}{ Any antihypertensive drug } \\
\hline Baseline & $3398(73.4)$ & $3418(73.1)$ & 0.90 \\
\hline Last study visit & $3409(73.6)$ & $3696(79.1)$ & $<0.001$ \\
\hline \multicolumn{4}{|l|}{ Lipid-lowering drug** } \\
\hline Baseline & $1782(38.5)$ & $1795(38.4)$ & 0.81 \\
\hline Last study visit & $2298(49.6)$ & $2361(50.5)$ & 0.27 \\
\hline \multicolumn{4}{|l|}{ Aspirin or other antiplatelet drug } \\
\hline Baseline & $1729(37.3)$ & $1696(36.3)$ & 0.50 \\
\hline Last study visit & $2103(45.4)$ & $2130(45.6)$ & 0.64 \\
\hline
\end{tabular}




\begin{tabular}{|cccc|}
\hline Table 1. (Continued.) & & & \\
\hline \\
Characteristic & Valsartan & Placebo & P Value \\
Antidiabetic drug & $(\mathbf{N}=4631)$ & $\mathbf{( N = 4 6 7 5 )}$ & . \\
Baseline & & $6(0.1)$ & 0.06 \\
Last study visit & $1(<0.1)$ & $733(15.7)$ & $<0.001$ \\
\hline
\end{tabular}

* Plus-minus values are means \pm SD. Cochran-Mantel-Haenszel tests were used for categorical variables; $F$ tests (variance ratio tests) were used for continuous variables. Both tests were stratified according to the use or nonuse of the other study drug (nateglinide) and presence or absence of a history of cardiovascular disease, except for cardiovascular disease or risk factors, which were stratified according to age ( $<55$ years or $\geq 55$ years). To convert the values for glucose to milligrams per deciliter, divide by 0.05551 . To convert the values for cholesterol to millimoles per liter, multiply by 0.02586 . To convert the values for triglycerides to millimoles per liter, multiply by 0.01129 . To convert the values for creatinine to micromoles per liter, multiply by 88.4. ACE denotes angiotensin-converting enzyme, GFR glomerular filtration rate, HDL high-density lipoprotein, and LDL low-density lipoprotein.

$\dagger$ Race was reported by investigators.

$\mp$ The body-mass index (the weight in kilograms divided by the square of the height in meters) was adjusted for sex. $\int$ The metabolic syndrome was defined according to the guidelines of the International Diabetes Federation. ${ }^{23}$

9 The estimated glomerular filtration rate was calculated with the use of the modified formula from the Modification of Diet in Renal Disease study for traceable serum creatinine values as measured by isotope-dilution mass spectrometry. ${ }^{24}$

|| The last study visit was the last time point at which the investigator indicated whether the patient had been taking a concomitant medication. Such a visit was either the end-of-study visit or the last recorded visit before death or withdrawal from the study.

$* *$ Statin use increased from 34 to $47 \%$ in the valsartan group and from 34 to $49 \%$ in the placebo group.

No interaction between valsartan and nateglinide was observed for any of the outcomes described (Section 6 in Supplementary Appendix 1).

\section{STUDY OUTCOMES}

\section{Coprimary Diabetes Outcome}

Diabetes mellitus developed in 1532 patients (33.1\%) in the valsartan group and 1722 patients $(36.8 \%)$ in the placebo group (Table 2 and Fig. 3 ). The hazard ratio for this outcome in the valsartan group, as compared with the placebo group, was 0.86 (95\% CI, 0.80 to 0.92 ; $\mathrm{P}<0.001$ in both one-sided and two-sided tests). The effect of valsartan on progression to diabetes was consistent across all prespecified subgroups (Section 7A in Supplementary Appendix 1). The proportion of patients who were taking an antidiabetic medication at their last study visit was smaller in the valsartan group than in the placebo group $(\mathrm{P}<0.001)$ (Table 1).

\section{Glycemia}

During the study, the fasting plasma glucose level was reduced by a mean of $0.59 \mathrm{mg}$ per deciliter ( $95 \%$ CI, 0.16 to 1.02$)$ ( $0.03 \mathrm{mmol}$ per liter [95\% $\mathrm{CI}, 0.01$ to 0.06$]$ ) in the valsartan group, as compared with the placebo group ( $\mathrm{P}<0.01)$ (Fig. $2 \mathrm{E}$ ). The plasma glucose level 2 hours after a glucose load was reduced by a mean of $3.15 \mathrm{mg}$ per deci- liter ( $95 \%$ CI, 1.58 to 4.72 ) ( $0.17 \mathrm{mmol}$ per liter [ $95 \% \mathrm{CI}, 0.09$ to 0.26$]$ ) in the valsartan group $(\mathrm{P}<0.001)$ (Fig. 2F).

\section{Coprimary Cardiovascular Outcomes}

The extended cardiovascular outcome occurred in 672 patients $(14.5 \%)$ in the valsartan group and 693 patients (14.8\%) in the placebo group (Table 2 and Fig. 3). The hazard ratio for this outcome in the valsartan group, as compared with the placebo group, was 0.96 (95\% CI, 0.86 to 1.07; $\mathrm{P}=0.22$ in a one-sided test; $\mathrm{P}=0.43$ in a two-sided test). The core cardiovascular outcome occurred in $375 \mathrm{pa}-$ tients $(8.1 \%)$ in the valsartan group and $377 \mathrm{pa-}$ tients $(8.1 \%)$ in the placebo group (hazard ratio, $0.99 ; 95 \% \mathrm{CI}, 0.86$ to $1.14 ; \mathrm{P}=0.42$ in a one-sided test; $\mathrm{P}=0.85$ in a two-sided test). The neutral effect of treatment was consistent for both outcomes across all prespecified subgroups (Sections 7B and $7 \mathrm{C}$ in Supplementary Appendix 1).

\section{Exploratory Outcomes, Including Death}

There was no significant difference between the study groups with respect to any of the components of the extended cardiovascular outcome or the prespecified exploratory outcomes (Table 2). The numbers of deaths were 295 (6.4\%) in the valsartan group and 327 (7.0\%) in the placebo group $(\mathrm{P}=0.17)$. 


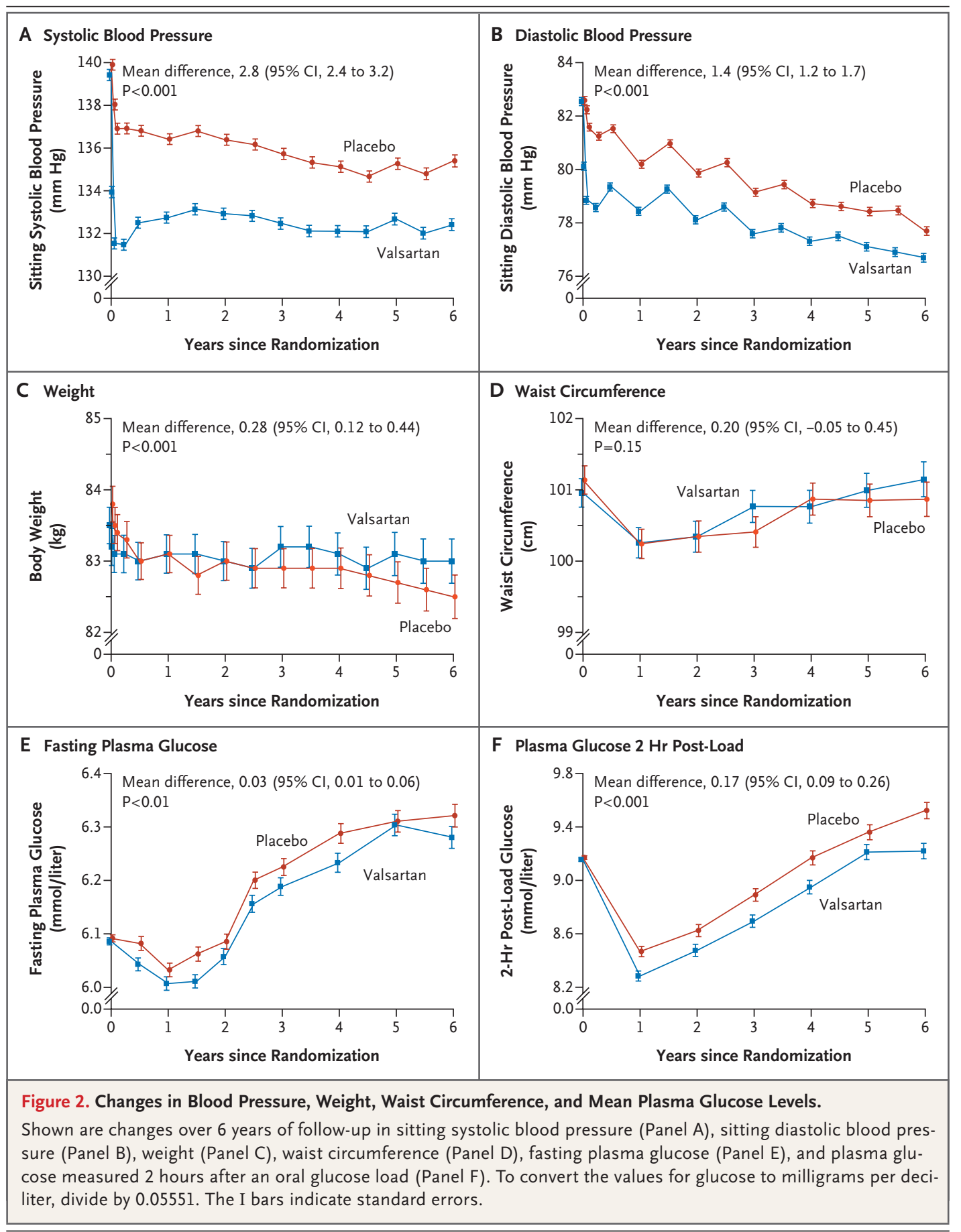

\section{ADVERSE EVENTS AND DISCONTINUATION OF STUDY DRUG}

Nasopharyngitis, back pain, and arthralgia were the most commonly reported individual adverse events (for a complete list, see Section 8 in Supplementary Appendix 1). There was no excess of renal dysfunction or hyperkalemia in the valsartan group, but hypotension-related adverse events were more common in the valsartan group (occurring in $42.4 \%$ of patients) than in the placebo group $(35.9 \%)(\mathrm{P}<0.001)$. During the course of the study, 556 patients $(12.0 \%)$ in the valsartan group and $531(11.4 \%)$ in the placebo group discontinued the study drug because of an adverse event $(\mathrm{P}=0.33)$. 


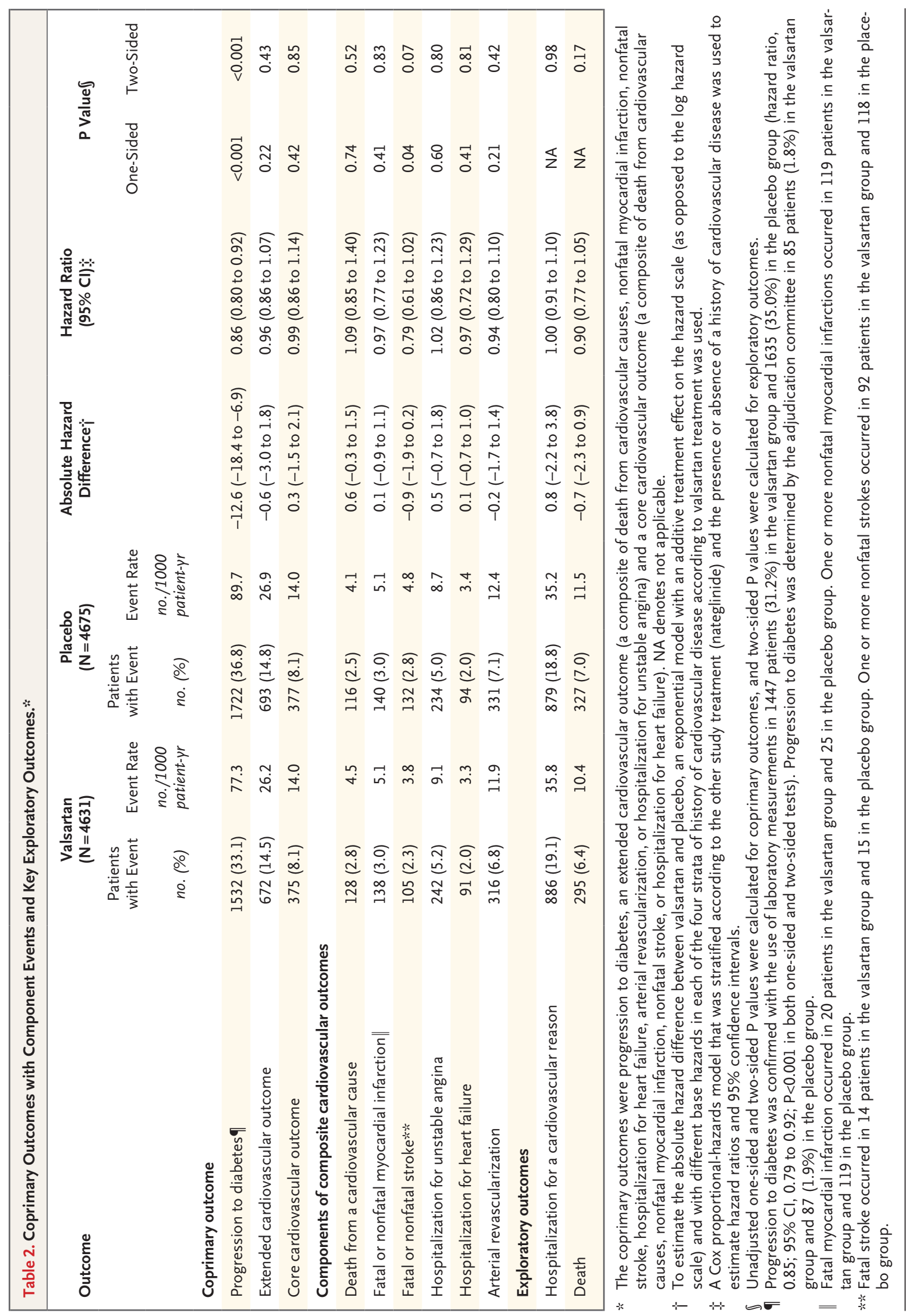




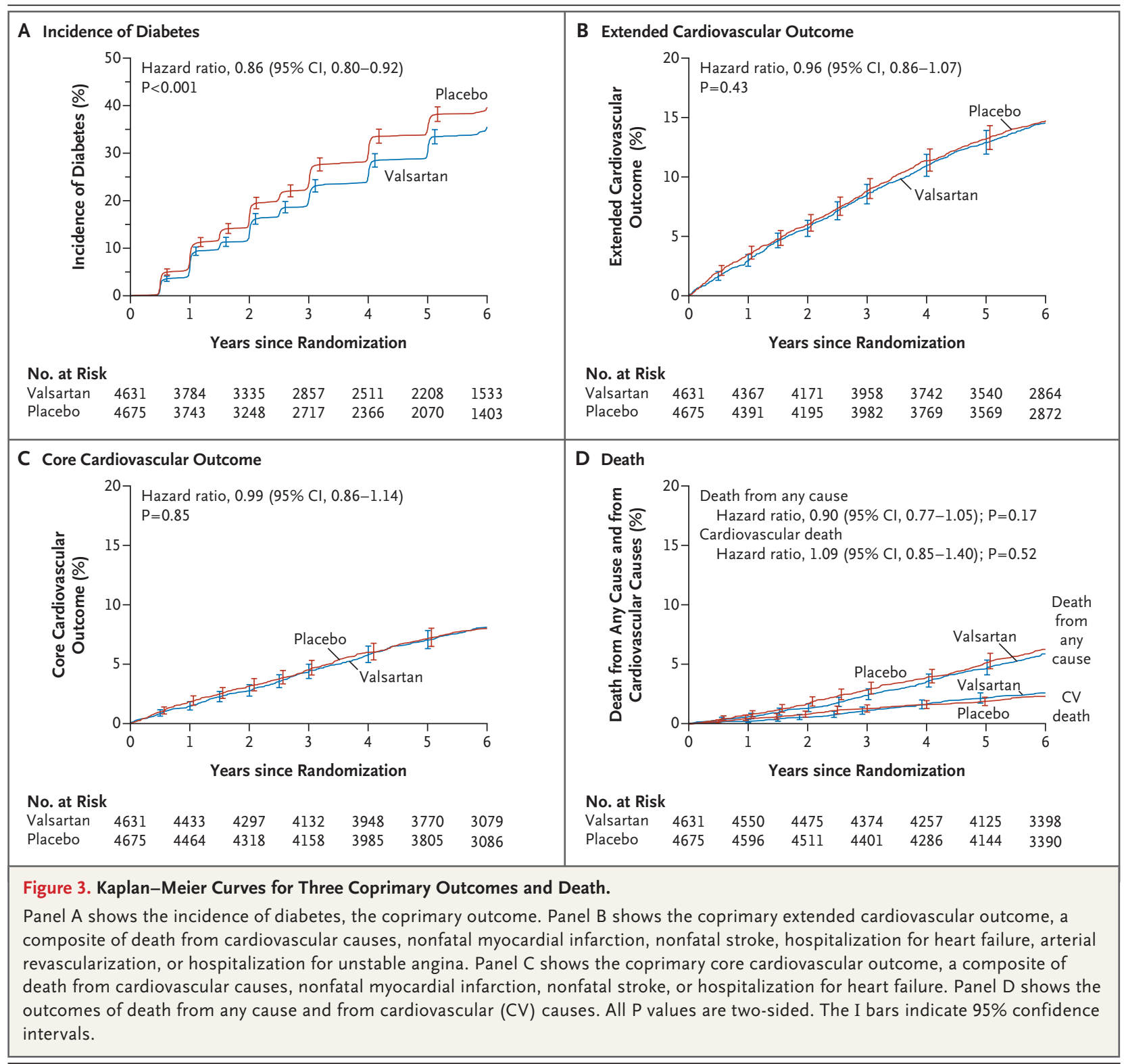

\section{DISCUSSION}

When added to lifestyle intervention, a single daily dose of valsartan (up to $160 \mathrm{mg}$ ) reduced the risk of diabetes but not of cardiovascular events in patients with impaired glucose tolerance and established cardiovascular disease or risk factors. The relative reduction of $14 \%$ in the risk of diabetes in the valsartan group would translate into 38 fewer cases of diabetes per 1000 patients treated for 5 years, a reduction that was consistent across all subgroups that we examined.
The decline was smaller than that suggested by pooled analyses of previous trials of ACE inhibitors and ARBs, which suggested a risk reduction of 25 to $30 \% .{ }^{11-15,25}$ However, these trials differed from our study in that not all subjects had impaired glucose tolerance, ascertainment and other biases may have led to an overestimation of the effect of these drugs, and study treatment did not include lifestyle modification. ${ }^{26}$ In addition, by the end of follow-up in our study, $24 \%$ of patients in the placebo group were taking an open-label ACE inhibitor or ARB, and many pa- 
tients in the valsartan group had discontinued the study treatment, which probably reduced the observed effect of the drug.

Despite these factors, the effect of valsartan was greater than that of an ACE inhibitor in the only previous trial that had the development of diabetes or death as the prospectively defined primary outcome. In the DREAM study, there was a nonsignificant trend toward a reduction in the incidence of diabetes in the ramipril group, with 449 patients who had diabetes in the ramipril group, as compared with 489 in the placebo group (hazard ratio, $0.91 ; 95 \% \mathrm{CI}, 0.80$ to $1.03 ; \mathrm{P}=0.15$ ), over a median follow-up period of 3 years. ${ }^{16}$ The mechanism by which inhibitors of the reninangiotensin system reduce the incidence of diabetes is unknown. ${ }^{27-30}$

Although indirect comparisons can be misleading, the effect of valsartan was smaller than that of lifestyle modification, which reduced the incidence of diabetes by $58 \%$ in two trials. ${ }^{5,6}$ However, in these two studies, the patient populations differed from that in our study, and the study periods were shorter. In addition, we tested the effect of valsartan combined with lifestyle modification. The effect of valsartan was also smaller than that of acarbose, metformin, or rosiglitazone, medications that have a recognized glucoselowering action, although none of these drugs were tested in addition to lifestyle modification or for as long as valsartan.

There are several possible reasons that valsartan did not improve cardiovascular outcomes, as expected. Our patients differed from those in previous trials of renin-angiotensin antagonists with cardiovascular outcomes in that all the patients had impaired glucose tolerance, only a minority (24\%) had established cardiovascular disease, and blood pressure was relatively well controlled. The benefit of renin-angiotensin system blockade has also been smaller in recent studies than observed historically, possibly because of greater use of other risk-reducing therapies. ${ }^{14,31-33}$ The patients with cardiovascular disease in our study were extensively treated with such therapies, including an ACE inhibitor in $22 \%$ of patients at baseline, and the use of nonstudy therapies, including openlabel ACE inhibitors and ARBs, increased during follow-up. These factors, coupled with the discontinuation of valsartan in a substantial proportion of patients, may have diluted any potential benefit of valsartan. Furthermore, lifestyle modification improves cardiovascular risk factors ${ }^{34}$ and, in the long term, may also reduce the rate of cardiovascular events. ${ }^{35}$ Finally, the most convincing evidence of improved cardiovascular outcomes with valsartan comes from trials in which patients received twice the daily dose that we used. ${ }^{36,37}$

Although lifestyle modification should remain the primary intervention to reduce the risk of diabetes in the general population, our findings may have implications for the treatment of hypertension, since the use of both thiazide diuretics and beta-blockers has been associated with an increased risk of diabetes. ${ }^{27-29}$

In conclusion, when added to a lifestyle intervention, valsartan at a daily dose of $160 \mathrm{mg}$ reduced the risk of diabetes but did not affect cardiovascular outcomes in patients with impaired glucose tolerance. No safety concerns were identified.

\section{Supported by Novartis Pharma.}

Disclosure forms provided by the authors are available with the full text of this article at NEJM.org.

We thank Teresa Gerlock, Lineke Zuurman, Patricia Kobi, Christian Leisner, Georgios Foteinos, Annette Meier, Virginie Marconot, Debra Gordon, Stephanie Le Breton, Andrea Fabel, and Stephanie Heiss of Novartis Pharma for their contributions; Anthony Doll of the Duke Clinical Research Institute (DCRI) for assistance with earlier versions of the figures; Tim Collier for the independent statistical analysis; and Jonathan McCall, also of the DCRI, for assistance in the preparation of the manuscript.

\section{APPENDIX}

The authors are as follows: John J. McMurray, M.B., Ch.B., M.D., Rury R. Holman, M.B., Ch.B., F.R.C.P., Steven M. Haffner, M.D., M. Angelyn Bethel, M.D., Björn Holzhauer, Dipl.Math., Tsushung A. Hua, Ph.D., Yuri Belenkov, M.D., Ph.D., Mitradev Boolell, M.D., John B. Buse, M.D., Ph.D., Brendan M. Buckley, M.D., D.Phil., Antonio R. Chacra, M.D., Ph.D., Fu-Tien Chiang, M.D., Bernard Charbonnel, M.D., Chun-Chung Chow, M.B., B.S., F.R.C.P., Melanie J. Davies, M.B., Ch.B., M.D., F.R.C.P., Prakash Deedwania, M.D., Peter Diem, M.D., Daniel Einhorn, M.D., Vivian Fonseca, M.D., Gregory R. Fulcher, M.B., B.S., M.D., F.R.A.C.P., Zbigniew Gaciong, M.D., Ph.D., Sonia Gaztambide, M.D., Ph.D., Thomas Giles, M.D., Edward Horton, M.D., Hasan Ilkova, M.D., Trond Jenssen, M.D., Steven E. Kahn, M.B., Ch.B., Henry Krum, M.D., Ph.D., Markku Laakso, M.D., Ph.D., Lawrence A. Leiter, M.D., Naomi S. Levitt, M.D., Viacheslav Mareev, M.D., Ph.D., Felipe Martinez, M.D., Chantal Masson, R.N., Theodore Mazzone, M.D., Eduardo Meaney, M.D., Ph.D., Richard Nesto, M.D., Changyu Pan, M.D., Rudolf Prager, M.D., Sotirios A. Raptis, M.D., Ph.D., Guy E.H.M. Rutten, M.D., Ph.D., Herbert Sandstroem, M.D., Frank Schaper, M.D., Andre Scheen, M.D., Ph.D., Ole Schmitz, M.D., Isaac Sinay, M.D., Vladimir Soska, M.D., Steen Stender, M.D., Gyula Tamás, M.D., Ph.D., Gianni Tognoni, M.D., Jaako Tuomilehto, M.D., Ph.D., Alberto S. Villamil, M.D., Juraj Vozár, M.D., Ph.D., and Robert M. Califf, M.D., on behalf of the NAVIGATOR Investigators.

The following are the authors' affiliations: the British Heart Foundation, Glasgow Cardiovascular Research Centre, University of Glasgow, Glasgow, United Kingdom (J.J.M.); Diabetes Trials Unit, Oxford Centre for Diabetes, Endocrinology, and Metabolism, Uni- 
versity of Oxford, Oxford, United Kingdom (R.R.H., M.A.B.); University of Texas Health Science Center, San Antonio, TX (S.M.H.); Duke Clinical Research Institute, Duke University, Durham, NC (M.A.B.); Novartis Pharma, Basel, Switzerland (B.H., M.B., C.M.); Novartis Pharmaceuticals, East Hanover, NJ (T.A.H.); Lomonosov Moscow State University, Moscow (Y.B., V.M.); the Division of General Medicine and Clinical Epidemiology, Diabetes Care Center, University of North Carolina School of Medicine, Chapel Hill, NC (J.B.B.); University College Cork, Cork, Ireland (B.M.B.); Federal University of São Paulo, São Paulo (A.R.C.); the Department of Cardiology, National Taiwan University Hospital, Taipei (F.-T.C.); the Endocrinology Department, University Hospital, Nantes, France (B.C.); the Department of Medicine and Therapeutics, Prince of Wales Hospital, the Chinese University of Hong Kong, Hong Kong (C.-C.C.); the Department of Cardiovascular Sciences, University of Leicester, Leicester, United Kingdom (M.J.D.); the Division of Cardiology, University of California-San Francisco Program at Fresno and Veterans Affairs (VA) Central California Health Care System, Fresno (P. Deedwania); the Division of Endocrinology Diabetes and Clinical Nutrition, Inselspital, University Hospital and University of Bern, Bern, Switzerland (P. Diem); the University of California, San Diego, and Scripps Whittier Diabetes Institute, La Jolla (D.E.); the Endocrinology Department, Tulane University, New Orleans (V.F.); Royal North Shore Hospital, University of Sydney, Sydney (G.R.F.); the Department of Internal Medicine, Hypertension, and Vascular Diseases, Warsaw Medical University, Warsaw (Z.G.); the Department of Endocrinology, Hospital Universitario de Cruces, CIBERDEM, Barakaldo, Spain (S.G.); the Heart and Vascular Institute, Tulane University School of Medicine, New Orleans (T.G.); Joslin Diabetes Center, Boston (E.H.); the Department of Endocrinology, Diabetes, and Metabolism, Istanbul University, Istanbul (H.I.); Oslo University Hospital Rikshospitalet, Oslo, and Institute of Clinical Medicine, University of Troms $\phi$, Troms $\phi$, Norway (T.J.); VA Puget Sound Health Care System and University of Washington, Seattle (S.E.K.); the Clinical Pharmacology Unit, Department of Epidemiology and Preventive Medicine, Monash University-Alfred Hospital, Prahan, VIC, Australia (H.K.); University of Kuopio and Kuopio University Hospital, Kuopio, Finland (M.L.); Keenan Research Centre, Li Ka Shing Knowledge Institute of St. Michael's Hospital, University of Toronto, Toronto (L.A.L.); the Department of Medicine, Groote Schuur Hospital, University of Cape Town, Cape Town, South Africa (N.S.L.); Cordoba National University, Cordoba, Argentina (F.M.); the Department of Diabetes and Metabolism, University of Illinois, Chicago (T.M.); Hospital Primero de Octubre, Mexico City (E.M.); Lahey Clinic, Burlington, MA (R.N.); the Department of Endocrinology, 301 Hospital, Beijing (C.P.); Hietzig Hospital (Krankenhaus Hietzing mit Neurologischen Zentrum Rosenhügel), Vienna (R.P.); the Second Department of Internal Medicine, Endocrinology, and Diabetology, Attikon University Hospital, Hellenic National Diabetes Center, Athens (S.A.R.); Julius Center for Health Sciences and Primary Care, University Medical Center, Utrecht, the Netherlands (G.E.H.M.R.); the Department of Public Health and Clinical Medicine, Umea University, Umea, Sweden (H.S.); the Center for Clinical Studies, Metabolism and Endocrinology Knowledge, and Technology-Transfer of Dresden University of Technology, Dresden, Germany (F.S.); the Division of Diabetes and Clinical Pharmacology Unit, Centre Hospitalier Universitaire de Liège, University of Liège, Liège, Belgium (A.S.); Medical Department M-Endocrinology and Diabetes, and the Department of Clinical Pharmacology, Århus University, Århus, Denmark (O.S.); Instituto Cardiovascular de Buenos Aires, Buenos Aires (I.S.); the Department of Clinical Biochemistry and Second Clinic of Internal Medicine, Faculty Hospital of St. Anna, Brno, Czech Republic (V.S.); the Department of Clinical Biochemistry, Gentofte Hospital, University of Copenhagen, Copenhagen (S.S.); 1st Department of Medicine, Diabetes Unit, Semmelweis University, Budapest, Hungary (G. Tamás); Consorzio Mario Negri Sud, Santa Maria Imbaro, Italy (G. Tognoni); Hjelt Institute and the Department of Public Health, Helsinki University, Helsinki, and South Ostrobothnia Central Hospital, Seinajoki, Finland (J.T.); the Hypertension Unit, Division of Cardiology, Argerich Hospital, University of Buenos Aires, Buenos Aires (A.S.V.); Diabetologic Outpatient Clinic, Jesenius Samaria, Šamorín, Slovak Republic (J.V.); and the Duke Translational Medicine Institute, Duke University, Durham, NC (R.M.C.).

\section{REFERENCES}

1. Edelstein SL, Knowler WC, Bain RP, et al. Predictors of progression from impaired glucose tolerance to NIDDM: an analysis of six prospective studies. Diabetes 1997;46:701-10.

2. Glucose tolerance and mortality: comparison of WHO and American Diabetes Association diagnostic criteria. Lancet 1999;354:617-21.

3. Nathan DM, Davidson MB, DeFronzo RA, et al. Impaired fasting glucose and impaired glucose tolerance: implications for care. Diabetes Care 2007;30:753-9.

4. Pan XR, Li GW, Hu YH, et al. Effects of diet and exercise in preventing NIDDM in people with impaired glucose tolerance: the Da Qing IGT and Diabetes Study. Diabetes Care 1997;20:537-44.

5. Tuomilehto J, Lindström J, Eriksson JG, et al. Prevention of type 2 diabetes mellitus by changes in lifestyle among subjects with impaired glucose tolerance. N Engl J Med 2001;344:1343-50.

6. Diabetes Prevention Program Research Group. Reduction in the incidence of type 2 diabetes with lifestyle intervention or metformin. $\mathrm{N}$ Engl $\mathrm{J}$ Med 2002;346:393-403.

7. Bethel MA, Califf RM. Role of lifestyle and oral anti-diabetic agents to prevent type 2 diabetes mellitus and cardio- vascular disease. Am J Cardiol 2007;99: 726-31.

8. Gillies CL, Abrams KR, Lambert PC, et al. Pharmacological and lifestyle interventions to prevent or delay type 2 diabetes in people with impaired glucose tolerance: systematic review and meta-analysis. BMJ 2007;334:299.

9. Chiasson JL, Josse RG, Gomis R, et al. Acarbose for prevention of type 2 diabetes mellitus: the STOP-NIDDM randomised trial. Lancet 2002;359:2072-7.

10. DREAM (Diabetes REduction Assessment with ramipril and rosiglitazone Medication) Trial Investigators. Effect of rosiglitazone on the frequency of diabetes in patients with impaired glucose tolerance or impaired fasting glucose: a randomised controlled trial. Lancet 2006;368:1096-105. [Erratum, Lancet 2006;368:1770.]

11. Yusuf S, Gerstein H, Hoogwerf B, et al. Ramipril and the development of diabetes. JAMA 2001;286:1882-5.

12. Kjeldsen SE, Julius S, Mancia G, et al. Effects of valsartan compared to amlodipine on preventing type 2 diabetes in high-risk hypertensive patients: the VALUE trial. J Hypertens 2006;24:1405-12.

13. Yusuf S, Ostergren JB, Gerstein HC, et al. Effects of candesartan on the devel- opment of a new diagnosis of diabetes mellitus in patients with heart failure. Circulation 2005;112:48-53. [Erratum, Circulation 2005:112(7):e292.]

14. The PEACE Trial Investigators. Angiotensin-converting-enzyme inhibition in stable coronary artery disease. $\mathrm{N}$ Engl J Med 2004;351:2058-68.

15. Abuissa H, Jones PG, Marso SP, O'Keefe JH Jr. Angiotensin-converting enzyme inhibitors or angiotensin receptor blockers for prevention of type 2 diabetes: a meta-analysis of randomized clinical trials. J Am Coll Cardiol 2005;46:821-6.

16. The DREAM Trial Investigators. Effect of ramipril on the incidence of diabetes. N Engl J Med 2006;355:1551-62.

17. Califf RM, Boolell M, Haffner SM, et al. Prevention of diabetes and cardiovascular disease in patients with impaired glucose tolerance: rationale and design of the Nateglinide And Valsartan in Impaired Glucose Tolerance Outcomes Research (NAVIGATOR) Trial. Am Heart J 2008;156:623-32.

18. The NAVIGATOR Study Group. Effect of nateglinide on the incidence of diabetes and cardiovascular events. N Engl J Med 2010. DOI: 10.1056/NEJMoa1001122. 19. Bethel MA, Holman R, Haffner SM, et al. Determining the most appropriate 
components for a composite clinical trial outcome. Am Heart J 2008;156:633-40.

20. Report of the Expert Committee on the Diagnosis and Classification of Diabetes Mellitus. Diabetes Care 1997;20: 1183-97.

21. Alberti KG, Zimmet PZ. Definition, diagnosis and classification of diabetes mellitus and its complications. 1. Diagnosis and classification of diabetes mellitus provisional report of a WHO consultation. Diabet Med 1998;15:539-53.

22. Lan KKG, DeMets DL. Discrete sequential boundaries for clinical trials. Biometrika 1983;70:659-63.

23. Alberti KG, Zimmet P, Shaw J, IDF Epidemiology Task Force Consensus Group. The metabolic syndrome - a new worldwide definition. Lancet 2005;366:1059-62. 24. Murthy K, Stevens LA, Stark PC, Levey AS. Variation in the serum creatinine assay calibration: a practical application to glomerular filtration rate estimation. Kidney Int 2005;68:1884-7.

25. Jandeleit-Dahm KA, Tikellis C, Reid CM, Johnston CI, Cooper ME. Why blockade of the renin-angiotensin system reduces the incidence of new-onset diabetes. J Hypertens 2005;23:463-73.

26. Ingelfinger JR, Solomon CG. Angiotensin-converting-enzyme inhibitors for impaired glucose tolerance - is there still hope? N Engl J Med 2006;355:1608-10.

27. Scheen AJ. Renin-angiotensin system inhibition prevents type 2 diabetes melli- tus. 2. Overview of physiological and biochemical mechanisms. Diabetes Metab 2004;30:498-505.

28. Gress TW, Nieto FJ, Shahar E, Wofford MR, Brancati FL. Hypertension and antihypertensive therapy as risk factors for type 2 diabetes mellitus. N Engl J Med 2000;342:905-12.

29. Barzilay JI, Davis BR, Cutler JA, et al Fasting glucose levels and incident diabetes mellitus in older nondiabetic adults randomized to receive 3 different classes of antihypertensive treatment: a report from the Antihypertensive and Lipid-Lowering Treatment to Prevent Heart Attack Trial (ALLHAT). Arch Intern Med 2006; 166:2191-201.

30. Elliott WJ, Meyer PM. Incident diabetes in clinical trials of antihypertensive drugs: a network meta-analysis. Lancet 2007;369: 201-7. [Erratum, Lancet 2007;369:1518.]

31. The Heart Outcomes Prevention Evaluation Study Investigators. Effects of an angiotensin-converting-enzyme inhibitor, ramipril, on cardiovascular events in highrisk patients. N Engl J Med 2000;342:145 53. [Errata, N Engl J Med 2000;342:748, 1376.]

32. Fox KM, EURopean trial On reduction of cardiac events with Perindopril in stable coronary Artery disease Investigators. Efficacy of perindopril in reduction of cardiovascular events among patients with stable coronary artery disease: randomised, double-blind, placebo-controlled, multi- centre trial (the EUROPA study). Lancet 2003;362:782-8.

33. Telmisartan Randomised AssessmeNt Study in ACE iNtolerant subjects with cardiovascular Disease (TRANSCEND) Investigators, Yusuf S, Teo K, et al. Effects of the angiotensin-receptor blocker telmisartan on cardiovascular events in high-risk patients intolerant to angiotensin-converting enzyme inhibitors: a randomised controlled trial. Lancet 2008;372:1174-83. [Erratum, Lancet 2008;372:1384.]

34. Ilanne-Parikka P, Eriksson JG, Lindström J, et al. Effect of lifestyle intervention on the occurrence of metabolic syndrome and its components in the Finnish Diabetes Prevention Study. Diabetes Care 2008;31:805-7.

35. Li G, Zhang P, Wang J, et al. The longterm effect of lifestyle interventions to prevent diabetes in the China Da Qing Diabetes Prevention Study: a 20-year follow-up study. Lancet 2008;371:1783-9.

36. Cohn JN, Tognoni G. A randomized trial of the angiotensin-receptor blocker valsartan in chronic heart failure. $\mathrm{N}$ Engl J Med 2001;345:1667-75.

37. Pfeffer MA, McMurray JJV, Velazquez EJ, et al. Valsartan, captopril, or both in myocardial infarction complicated by heart failure, left ventricular dysfunction, or both. N Engl J Med 2003;349:1893-906. [Erratum, N Engl J Med 2004;350:203.]

Copyright (๑) 2010 Massachusetts Medical Society. go to the Journal's home page (NEJM.org) and register by entering their names and subscriber numbers as they appear on their mailing labels. After this one-time registration, subscribers can use their passwords to log on for electronic access to the entire Journal from any computer that is connected to the Internet. Features include a library of all issues since January 1993 and abstracts since January 1975, a full-text search capacity, and a personal archive for saving articles and search results of interest. All articles can be printed in a format that is virtually identical to that of the typeset pages. Beginning 6 months after publication, the full text of all Original Articles and Special Articles is available free to nonsubscribers. 